06

\title{
Исследование электровзрывных нанопорошков никеля
}

\author{
( Г. Партизан, ${ }^{1,2}$ Б.З. Мансуров, ${ }^{1}$ Б.С. Медянова, ${ }^{1,2}$ А.Б. Кошанова, ${ }^{1,2}$ Б.А. Алиев ${ }^{2}$ \\ ${ }^{1}$ Институт проблем горения, \\ 050012 Алматы, Казахстан \\ ${ }^{2}$ Казахский национальный университет им. Аль-Фараби, \\ 050040 Алматы, Казахстан \\ e-mail: gulmira.partizan@gmail.com
}

(Поступило в Редакцию 17 февраля 2016 г.)

Представлены результаты комплексного исследования структуры и морфологии нанопорошков никеля, синтезированных методом электровзрывного испарения металлической проволоки. Результаты сканирующей и просвечивающей микроскопий показали, что нанокластеры имеют сферическую форму со средним диаметром $50 \mathrm{~nm}$. На основании анализа дифрактограмм установлено, что наночастицы электровзрывных нанопорошков обладают кристаллической решеткой с параметром ячейки больше стандартного. Результаты проведенных компьютерных экспериментов хорошо согласуются с выводами рентгеноструктурного анализа. Однако вопрос о причинах искажения кристаллической решетки нанокластеров остается дискуссионным.

\section{Введение}

Исследование свойств нанокластеров металлов вызывает в настоящее время повышенный интерес как с теоретической точки зрения, так и в силу многочисленных приложений. Это обусловлено необходимостью создания фундаментальных физических основ для дальнейшего развития нанотехнологий и широким использованием наночастиц и наноструктур в практических приложениях [1]. Интерес связан, в частности, с применением наночастиц переходных металлов $\mathrm{Ni}, \mathrm{Cu}, \mathrm{Fe}$ и др. в качестве катализаторов для синтеза углеродных наноструктур [2-4].

В настоящее время существует ряд химических и физических методов получения наночастиц металлов, их соединений и сплавов. Разделение является условным, так как химические реакции играют большую роль, например, при испарении в среде реакционных газов. В то же время многие химические методы основаны на физических явлениях (низкотемпературная плазма, лазерное излучение и др.) [1].

Одним из перспективных методов получения нанопорошков (НП) является электрический взрыв проводников (ЭВП) - неравновесный процесс, при котором под действием импульсного электрического тока проводник диспергируется, и продукты взрыва перемешиваются с окружающей средой. ЭВП НП обладают рядом преимуществ в сравнении с НП, полученными другими способами: устойчивы к окислению и спеканию при комнатной температуре, при нагревании характеризуются высокой химической и диффузионной активностью [5].

В настоящей работе представлены результаты исследований морфологии и структуры НП никеля, полученных методом ЭВП методами сканирующей и просвечивающей микроскопий, рентгеноструктурного анализа, а также компьютерных экспериментов, проведенных в программе ChemBio3D.

\section{1. Экспериментальная часть}

НП никеля были получены в Томском политехническом университете (Россия) группой профессора А.П. Ильина методом электровзрывного испарения металлической проволоки в атмосфере аргона. Процедура и детали экспериментов описаны в работах $[6,7]$.

Для изучения морфологии образцы были исследованы методом растровой электронной микроскопии в Отделе поверхности и технологий новых материалов Института материаловедения университета г. Зиген (Германия). Использовался автоэмиссионный сканирующий электронный микроскоп (СЭМ) сверхвысокого разрешения фирмы Zeiss модели Gemini Ultra 55, с устройством для рентгеноспектрального микроанализа от фирмы „Thermo Scientific“.

Исследования методом просвечивающей электронной микроскопии (ПЭМ) были проведены в Институте ядерной физики (Алматы, Казахстан) с помощью просвечивающего электронного микроскопа JEM-2100 JEOL. Для подготовки образцов НП суспензировались в этаналоне с чистотой 99.9\%. Далее проводилась ультразвуковая обработка раствора в течение $5 \mathrm{~min}$, после чего капли суспензии наносились на медную сетку.

Изучение структуры ЭВП НП $\mathrm{Ni}$ проводилось с помощью рентгеновского дифрактометра Philips X'Pert PRO MRD в Университете г. Зиген (Германия) с применением медного излучения $\left(\lambda\left(\mathrm{Cu}_{K \alpha 1}\right) \sim 0.15405 \mathrm{~nm}\right)$. Спектральная и угловая монохроматизации зондового пучка осуществлялись с помощью четырехкристального асимметричного монохроматора $\mathrm{Ge}$ (220). Обработка рентгенограмм для определения углового положения и интенсивностей рефлексов проводилась программой OriginPro 8.1. При проведении фазового анализа использовалась программа PCPDFWIN с базой дифрактометрических данных PDF-2.

Для оценки изменения параметра ячейки в нанокластерах в программе ChemBio3D Ultra были проведены 

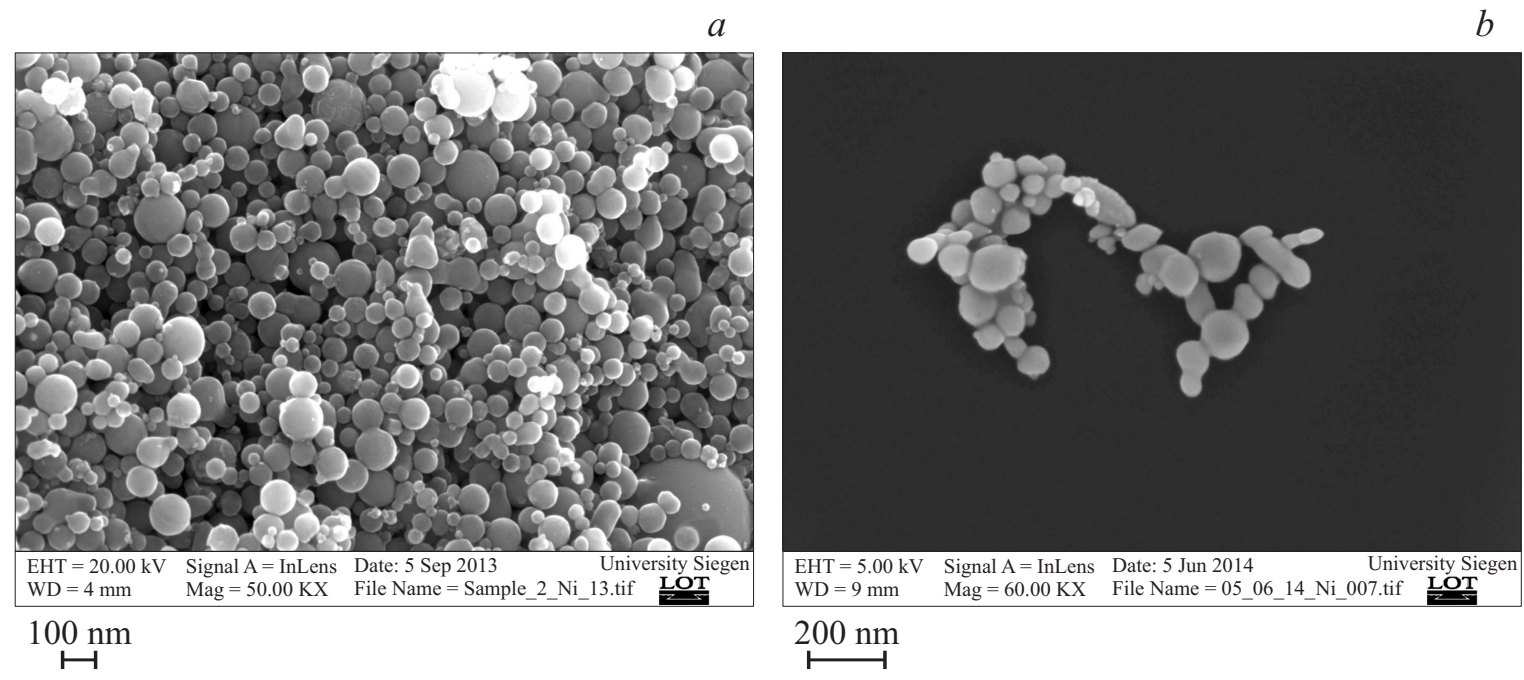

$b$

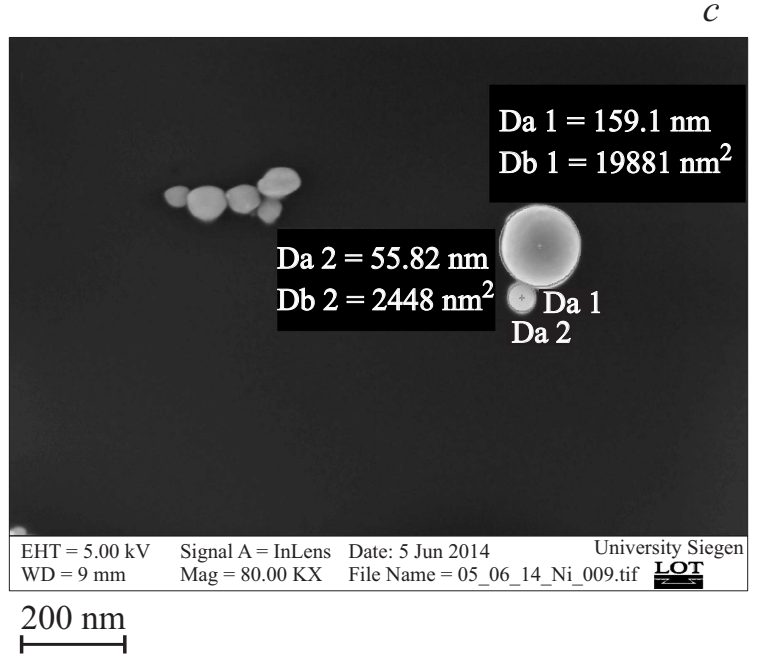

Рис. 1. СЭМ-изображения частиц НП никеля. Нанопорошки $(a)$, агломераты нанокластеров $(b)$ и отдельные нанокластеры $(c)$ после сепарации в гексане.

компьютерные эксперименты по минимизации энергии при разных температурах.

\section{2. Результаты и обсуждение}

\section{1. СЭМ-исследования}

На рис. 1 представлены СЭМ-изображения НП никеля и сепарированных образцов. Для проведения сепарации образцы НП суспензировались в гексане. Далее проводилась ультразвуковая обработка раствора (объем суспензии $30 \mathrm{ml}$, частота ультразвука $27 \mathrm{kHz}$, мощность генератора $120 \mathrm{~W}$, воздействие проводилось в течение $30 \mathrm{~min})$, после чего капли суспензии с частицами металла наносились на кремниевую подложку.

На СЕМ-изображениях видно, что размеры подавляющего числа частиц не превышают $100 \mathrm{~nm}$. При этом наблюдается образование цепочечных структур из мелких кластеров (от 10 до $30 \mathrm{~nm}$ ), а так же частичное их спекание между собой (образуются так называемые шейки). Форма частиц Ni близка к сферической. На рис. $2, b$ представлен энергодисперсионный (EDX) спектр ЭВП $\mathrm{H} \Pi \mathrm{Ni}$.

Как видно из спектра EDX, в составе порошка $\mathrm{Ni}$ присутствуют в незначительном количестве примеси углерода и кислорода, что является нормальным, так как наиболее устойчивым для никеля является состояние окисления. Наличие примеси углерода объясняется условиями процедуры пассивации порошков.

\section{2. Результаты ПЭМ}

На рис. 3 представлены ПЭМ-изображение и гистограмма распределения по размерам ЭВП НП Ni.

Результаты ПЭМ-исследований согласуются с данными, полученными с помощью СЭМ. На рис. $3, a$ видно, что частицы НП Ni имеют сферическую форму. Из данных гистограммы следует, что в образце преобладают частицы диаметром $40-70 \mathrm{~nm}$, средний диаметр 
$a$
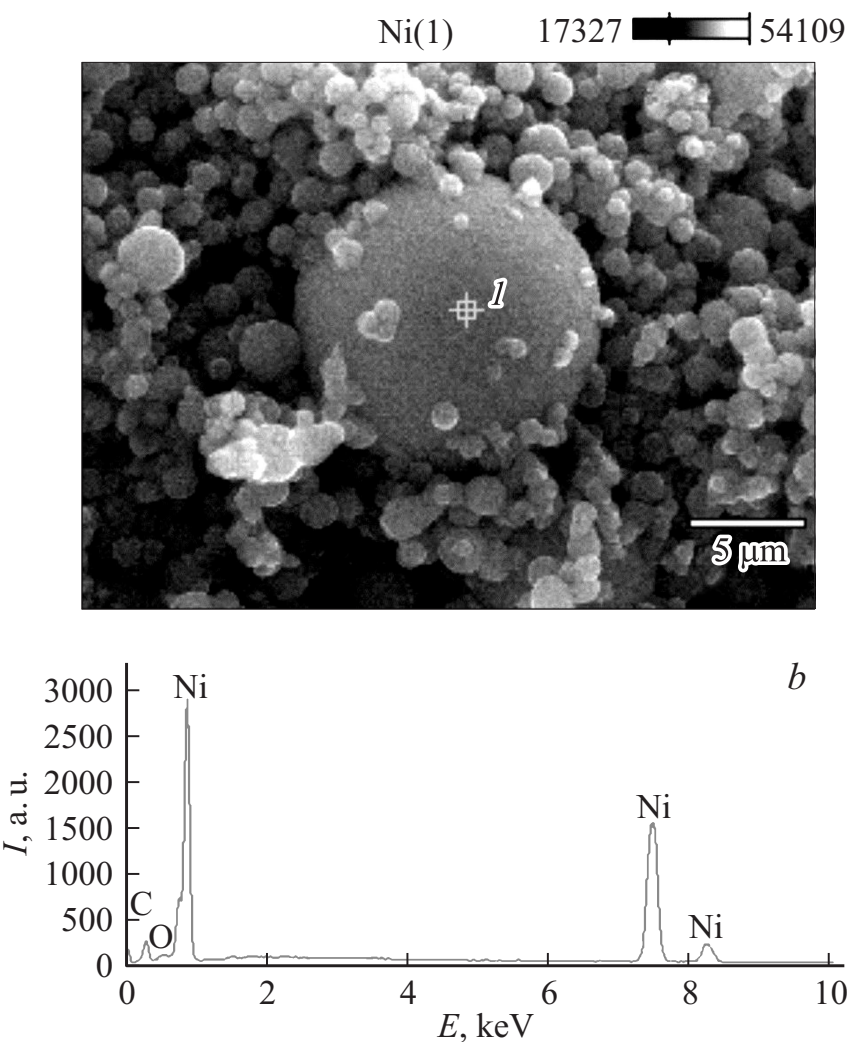

Рис. 2. Микрофотография порошка $\mathrm{Ni}(a)$ и энергодисперсионный рентгеновский спектр $(b)$.

которых равен $50 \mathrm{~nm}$. Анализ гистограммы показывает, что распределение наночастиц по размерам является гауссовым со значением среднеквадратического отклонения $\sigma=36.6 \mathrm{~nm}$.

\section{3. Результаты рентгеноструктурного анализа}

На рис. 4 представлена рентгенограмма ЭВП нанопорошков Ni. Из результатов рентгеноструктурного анализа следует, что основной фазой в составе исследованных образцов является термодинамически устойчивая кристаллическая модификация (пространственная группа симметрии $F m 3 m$ ), свойственная массивному состоянию (Ni-PDF \# 040850). Однако на рентгенограммах было обнаружено расщепление и асимметричность пиков. Расщепление пиков наблюдается в области максимумов (220), (311) и (222). Для всех трех плоскостей выявлено увеличение межплоскостного расстояния. Полученные результаты расщепления пиков могли себя проявить за счет размерных эффектов. В частности, в работе [8] это связывают с влиянием оксидного слоя.

При формировании на границе раздела металл/оксид возможно искажение решетки вследствие ориентирующего влияния решетки оксида металла (энергии кристаллических решеток отличаются в несколько раз). Однако в работе [1] расщепление пиков объясняется изменением параметра решетки нанокластеров металлов.

\section{4. Компьютерные эксперименты}

В последнее время метод молекулярной механики (MМM) широко используется для анализа структуры и свойств наноматериалов. Главная причина популярности МММ - скорость, которая делает его в вычислительном отношении выполнимым для обычного использования. Альтернативные методы для генерации молекулярной конфигурации, такие как $a b$ initio или полуэмпирические молекулярные орбитальные вычисления, требуют намного большего количества машинного времени и мощности персонального компьютера. Основная задача в вычислительной части МММ состоит в том, чтобы минимизировать энергию напряжения в молекулах, приближая атомные положения к оптимальной геометрии. Это означает уменьшение полной нелинейной энергии напряжения, представленной уравнением силового поля относительно независимых переменных, которые являются декартовыми координатами атомов [9]. Для оценки изменения параметра ячейки в нанокластерах в программе ChemBio3D Ultra были рассмотрены трехмерные модели (рис. 5) и проведены компьютерные эксперименты по минимизации энергии при разных температурах.
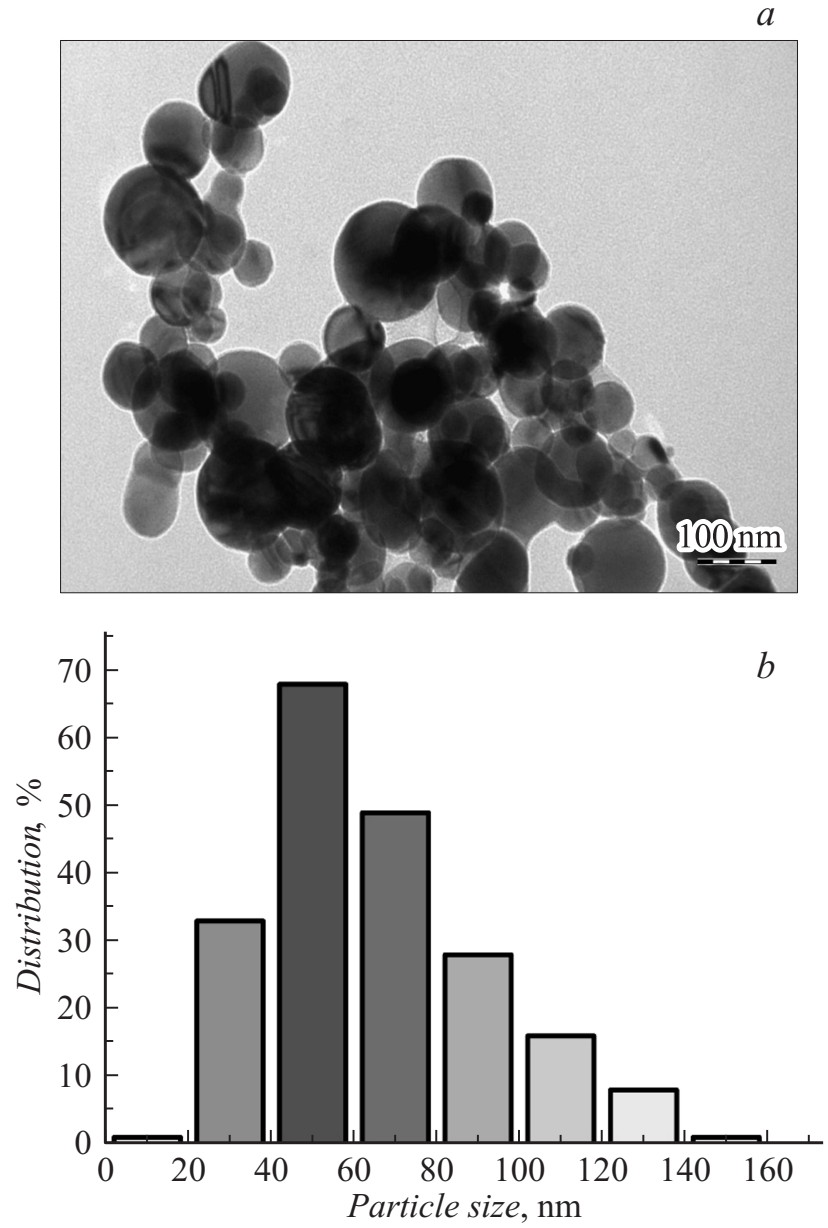

Рис. 3. ПЭМ-изображение НП $\mathrm{Ni}(a)$ и гистограмма распределения по размерам $(b)$. 


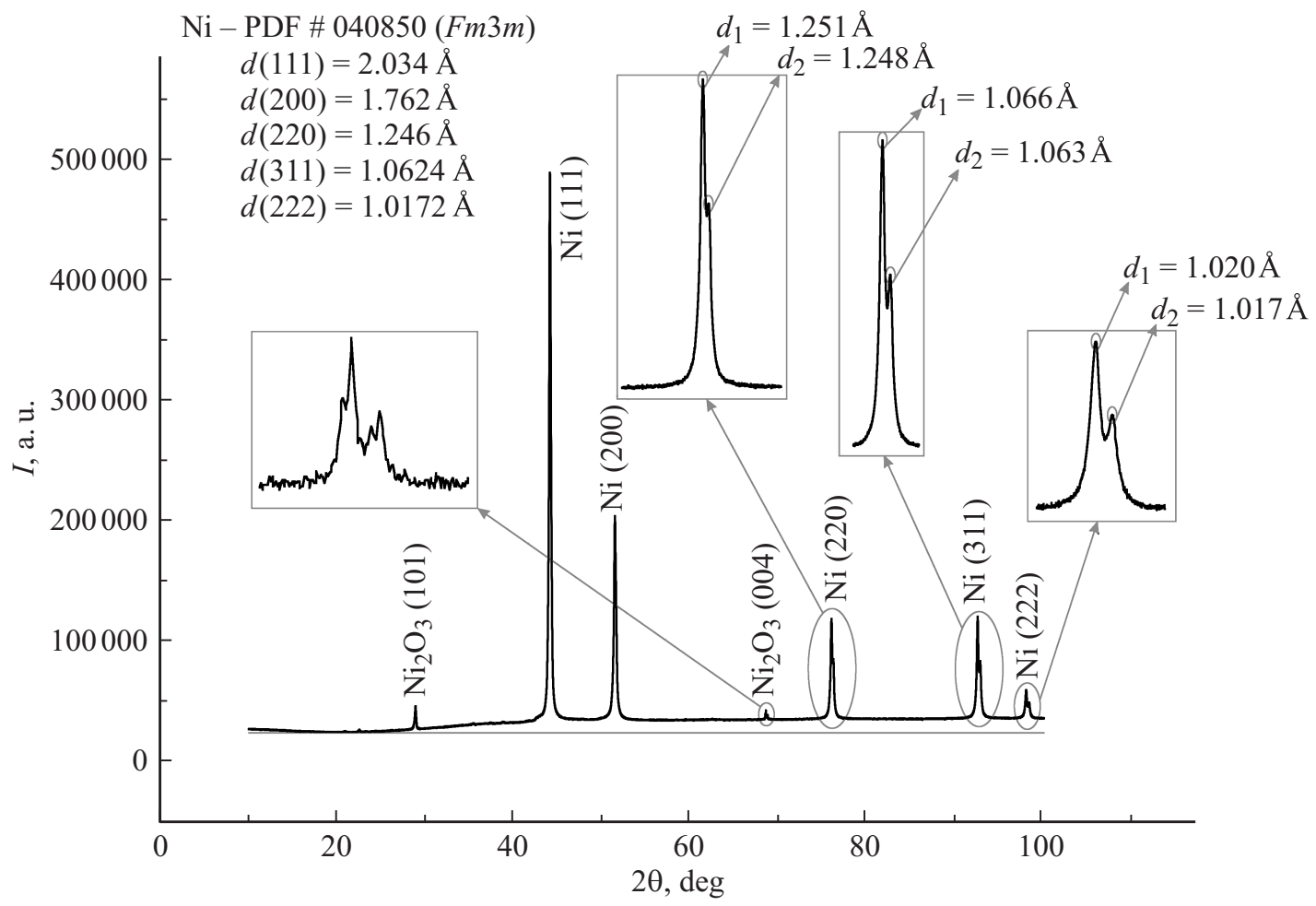

Рис. 4. Рентгенограмма ЭВП нанопорошков Ni.
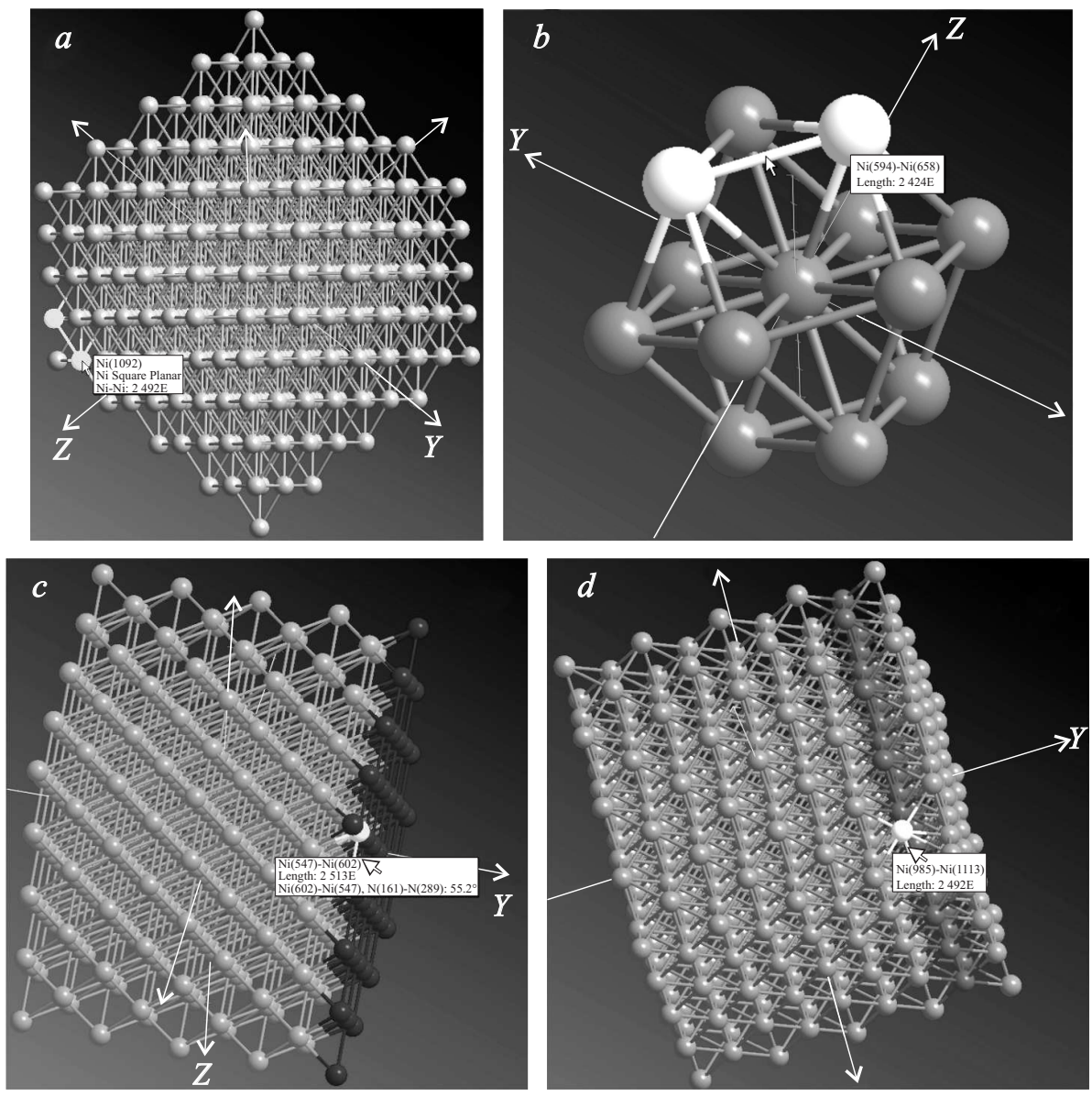

Рис. 5. Трехмерные модели нанокластеров никеля. $a-$ модель 3D нанокластера из 1152 атомов, $b-$ внутреннее ядро (ВЯ) 13 атомов, $c-$ поверхностный слой (ПС) - 64 атома, $d-$ приповерхностный слой $(П р С)-64$ атома. 


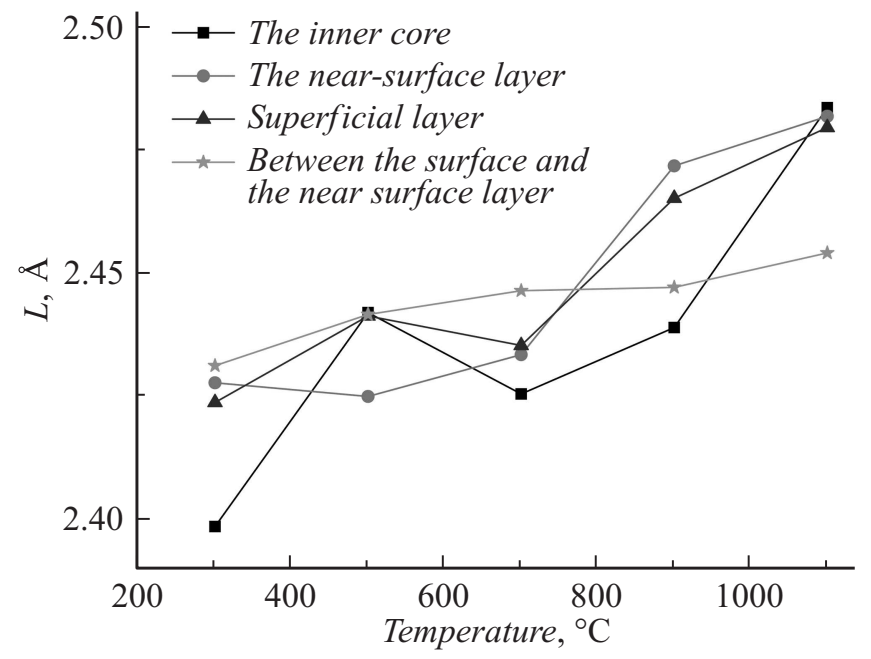

Рис. 6. Межатомные расстояния $(L)$ в нанокластерах, в зависимости от температуры.

При минимизации энергии [9-11] имеет место упругая деформация кристаллической решетки и соответственно смещение атомных координат. Основываясь на этом, были рассчитаны средние межатомные расстояния для внутренних и внешних атомов (рис. 6).

Из графика (рис. 6) видно, что с увеличением температуры увеличивается параметр решетки, что согласуется с данными рентгеноструктурного анализа.

На сегодняшний день не существует модели, позволяющей с единой точки зрения описать изменение температуры плавления, параметра решетки, а также экспериментально наблюдаемое огрубление поверхности нанокластеров металлов. Одним из эффектов, возникающих при уменьшении размеров кластеров, является изменение параметра решетки [12-17]. При этом в ряде случаев знак изменения параметра различен для частиц одних и тех же веществ и зависит от условия их получения. Так, например, имеются экспериментальные данные по уменьшению $[12,18]$, увеличению $[13,17]$ и отсутствию изменений $[14,19]$ параметра решетки в пределах ошибок для золотых кластеров, по сравнению с объемными образцами. Такая неоднозначность в экспериментальных результатах в значительной мере затрудняет ответ на вопрос, в какой мере изменение параметра обусловлено малостью размера, а в какой - другими факторами, например примесями, и каков механизм размерного изменения параметра решетки [1].

\section{Заключение}

СЕМ-исследования НП $\mathrm{Ni}$ показали, что размеры подавляющего числа частиц не превышает $100 \mathrm{~nm}$. При этом наблюдается образование цепочечных структур из мелких частиц (от 10 до $30 \mathrm{~nm}$ ), а так же частичное их спекание между собой. Форма частиц Ni близка к сферической. Результаты ПЭМ-исследований $\mathrm{HП} \mathrm{Ni}$ согласуются с результатами, полученными с помощью
СЭМ. Анализ дифрактограмм показал расщепление пиков, которое наблюдается в области максимумов (220), (311) и (222). Для всех трех плоскостей наблюдается увеличение межплоскостного расстояния. Компьютерные эксперименты показали результаты, которые хорошо согласуются с данными рентгеноструктурного анализа.

Таким образом, в ходе проведенных исследований было показано, что полученные в неравновестных условиях электровзрыва проводников наноразмерные частицы $\mathrm{Ni}$ обладают кристаллической структурой с параметром решетки, отличным от стандартного.

Авторы выражают глубокую благодарность за сотрудничество и предоставление аналитической базы директору Института материаловедения университета г. Зиген (Германия) проф. Ксин Джианга (Xin Jiang). Работа выполнена при частичной финансовой поддержке гранта Комитета Науки МОН РК № 3823/ГФ4.

\section{Список литературы}

[1] Автореф. канд. дис. Васильев О.С. Плавление, огрубление поверхности и электронные свойства нанокластеров металлов различной размерности.01.04.07. Москва. 2004. $120 \mathrm{c}$.

[2] Wang H., Yuan Y., Wei L., Goh K., Yu D., Chen Y. // Carbon. 2015. Vol. 81. P. 1-19.

[3] Yan Y., Miao J., Yang Zh., Xiao F., Yang H.B., Liu B., Yang Y. // Chem. Soc. Rev. 2015. Vol. 44. P. 3295-3346.

[4] Partizan G., Mansurov B.Z., Medyanova B.S., Aliev B.A., Xin Jiang. // J. Eng. Phys. Thermophys. 2015. Vol. 88. N 6. P. $1451-1458$.

[5] Лернер М.И., Сваровская Н.В., Псахье С.Г., Бакина О.В. // Российские нанотехнологии. 2009. Т. 4. Вып. 11-12. C. $56-68$.

[6] Автореф. канд. дис. Лернер М.И. Электровзрывные нанопорошки неорганических материалов: технология производства, характеристики, области применения. 01.04.07. Томск. 2007. $325 \mathrm{c}$.

[7] Ильин А.П. // Известия ТПУ. 2003. Т. 306. Вып. 1. C. $133-139$.

[8] Коршунов А.В. // Изв. ТПУ. 2012. Т. 320. Вып. 3. С. 16-22.

[9] Stan Tsai C. An Introduction to Computational Biochemistry. Wiley-Liss, Inc., 2002. 368 p.

[10] Соловьев М.Е., Соловьев М.М. Компьютерная химия. М.: СОЛОН-Пресс, 2005. 535 c.

[11] Partizan G., Mansurov B.Z., Medyanova B.S., Mansurova M.E., Aliyev B.A. // Proc. of the Annual Intern. World Conf. on Carbon. Jeju, Korea, 2014. POT3-02.

[12] Nepijko S.A., Pippel E., Woltersdorf J. // Phys. Stat. Sol. A. 1980. Vol. 61. N. 2. P. 469-475.

[13] Boswell F. // Proc. Phys. Soc. 1951. Vol. 64. P. 465-476.

[14] Vook R., Onooni M. // J. Appl. Phys. 1968. Vol. 39. P. 2471.

[15] Harada J., Yao S., Ichimiya A. // J. Phys. Soc. Japan. 1980. Vol. 48. P. 1625.

[16] Montano P., Shenoy G., Alp E. et al. // Phys. Rev. Letters. 1986. Vol. 56. N. 19. P. 2076.

[17] Onodera S. // J. Phys. Soc. Jap. 1992. Vol. 61. N. 7. P. 2190-2193.

[18] Solliard C., Flueli M. // Surf. Sci. 1985. Vol. 156. P. 487-494.

[19] Schamp C.T., Jesser W.A. // Ultramicroscopy. 2005. Vol. 103. N 2. P. 165-172. 